\title{
Dimensão cultural da integração na América Latina
}

\section{GUSTAVO BEYHAUT}

$\mathrm{N}$ o estudo deste primeiro aspecto da integração na América Latina enumeramos os obstáculos derivados da diversidade de culturas no interior de cada país ou regióes e que transcendem às suas fronteiras. Essa diversidade pode ser interpretada através da evolução histórica de etnias e formas sociais derivadas de uma evolução histórica regional.

Para iniciar essa enumeração podemos apresentar casos de regiōes sócio-culturais diversificadas. Como primeiro exemplo temos as formações indígenas que praticaram agricultura em grandes planaltos: a região chamada Alto Peru, compreendendo as zonas que vão desde Peru, Bolívia e norte do Chile até certas zonas do Equador, ou seja, países de formação andina.

Como segundo exemplo de regiáo sócio-cultural temos, ainda, as antigas sociedades indígenas de terras baixas onde predomina a selva. A região amazônica é o caso mais notório, integrando territórios cuja principal parcela está no Brasil, mas que se prolongam a certas zonas do sul da Venezuela, sul da Colômbia, leste peruano e parte do território boliviano.

Outra regiāo que podemos mencionar é a das antigas culturas guarani em zonas de Argentina, Paraguai, Brasil, oriente boliviano e terras do Uruguai (país este que resolveu seu problema indígena com o extermínio genocida dos sobreviventes da expansão de suas fronteiras). No caso guarani faz-se obrigatório lembrar a tentativa frustrada do império jesuítico, que terminou com a expulsão dos membros da Ordem em meados do século XVIII. Tem-se discutido muito o papel dos jesuítas com relação às sociedades indígenas que eles organizaram. Torna-se evidente a capacidade dessa Ordem para percorrer territórios e introduzir nas tribos indígenas outro sistema de vida. Os jesuítas demonstraram habilidade para o manejo das línguas aborígenes e para a comunicação com tribos que eram vítimas de perseguiçóes e domínio por parte dos 
conquistadores, os quais somente buscavam a exploração da mão-deobra.

A aldeia jesuítica estava bem-organizada, talvez até demasiadamente, demonstrando preocupaçáo em eliminar a pobreza e apoiando crianças e viúvas, por exemplo. A crítica fundamental que pode ser feita é que substituía o sistema de exploraçáo criticável por outro demasiadamente rígido, muito condicionado pelos interesses gerais da Ordem. É certo que a Companhia de Jesus enfrentou o capitalismo comercial implantado com resquícios feudais na América Latina nas zonas conquistadas, com ele competindo. A grande falha, contudo, é náo ter dado participação ao índio, nem haver-lhe capacitado para exercer auto-governo. Por isso, sua expulsáo gerou o caos e as chamadas guerras guarani.

Um quarto exemplo refere-se às sociedades de plantation e a contestação rebelde de suas populaçóes oprimidas. Neste caso, mais notória é a exploração massiva da cana-de-açúcar, utilizando mão-de-obra escrava de origem africana. Esse modelo de sociedade caracteriza-se pela introdução abundante de mão-de-obra forçada trazida da África, ou de seus descendentes; é no Brasil e no Caribe, fundamentalmente, onde aparecem os casos mais típicos. Náo sáo sistemas muito estáveis porque haveráo de lutar contra a rebeliáo da mão-de-obra explorada, constituindo outras formas de sociedades, das quais são claros exemplos os quilombos brasileiros e os maronages dos países do Caribe.

Em amplas zonas do norte do México - e parte dos territórios mexicanos conquistados pelos Estados Unidos - existiu também uma modalidade sócio-cultural de origem indígena, submetida à exploraçáo e discriminaçáo sob a forma de aculturafáo imposta, que contra a política de dominação e extermínio mostraram resistência de forma exemplar, transformando-se em nômades, bandidos e rebeldes. Os apaches, os comanches - e já entrando no século XX os movimentos de protesto social como o dos chamados chicanos - constituem modalidades desses sistemas contestatários. Em linhas gerais, as possibilidades de exploraçáo da mão-de-obra indígena serão mais fáceis em zonas agrárias, onde já existiam essas condiçōes antes da chegada do conquistador europeu. Com a política de dominação ou extermínio, outros índios são obrigados a moverem-se para zonas de selva ou de terra pobre de alta montanha.

Outro foco de resistência formar-se-á no sul da Argentina e Chile, onde os indígenas resistem à opressão dos novos estados surgidos da independência. Do lado chileno, a resistência foi muito forte ao sul do 
rio Bio Bio e, outras vezes, por migraçōes até territórios argentinos. O índio aprendeu a lutar contra o invasor europeu e assimilou as técnicas introduzidas pelos conquistadores: aprendeu a montar a cavalo e usar armas de fogo; abastecia-se em numerosas incursóes para apropriar-se de gado e alimentos diversos; e, muitas vezes, levou mulheres que se incorporaram a seu sistema de vida. Os métodos para dominá-lo foram verdadeiramente selvagens. Organizaram-se literalmente caças aos índios, pagando-se pela apresentação de suas orelhas, a fim de que se expandissem os latifúndios. Neste caso, muitas vezes eram feitos pactos com seus caciques.

A diversidade de culturas é relacionada com as etnias originais e com os sistemas de exploração e organização do poder. Aí há um campo de estudo bastante inexplorado, mas que apresenta aspectos muito interessantes. Concebeu-se falsamente o processo de conquista como rápido estabelecimento de um sistema de poder. $O$ fato é que se passaráo décadas e séculos de situaçóes indefinidas, reveladoras da coexistência de distintas formas sociais. Há capítulos inacabados dessas sociedades marginais e outros que cumpriram seu papel como, por exemplo, o mundo gaúcho, fronteira entre o mundo indígena e o de expansão produtora para o capitalismo comercial, que constitui uma modalidade específica em algumas regiôes do sul da América, mas não diferem essencialmente da resistência armada de gente como os bandidos da savana venezuelana. A tensão e opressão social explicam banditismos como o de Pancho Villa, o de cangaceiros brasileiros, ou certas formas de banditismo de espírito montonero, que caracterizavam a revolta social em países como a Argentina.

Há de ser dito que a imigração asiática substituiu, em muitas zonas, a carência de mão-de-obra consequiência da crise do sistema escravista, devido a fortes pressóes inglesas, que obedeciam a motivos mais econômicos que humanitários. A ruína do artesanato na Índia e na China criou o fluxo de coolies.

A situação de algumas ilhas do Caribe, em regime de contrabando e pirataria contra os monopólios comerciais, permitiu certas experiências de sociedades utópicas.

As fortes correntes de imigraçáo européia que se dirigem às zonas produtoras de café no Brasil, de cereal na Argentina, fundamentalmente criaram a falsa imagem de esses espaços caracterizarem o que se chamou de territórios vazios, constituindo evidentemente um erro, porque a mudança de densidade demográfica e a distinta origem dos povoadores não determinam o desaparecimento das formas tradicionais. 
O crescimento urbano pode ser identificado com o crescimento da civilização sobre as zonas rurais, que são apresentadas como representantes da barbárie. A cidade, e mais adiante as grandes cidades, produzem também formas de barbárie, embora diferentes. Mostramos aqui formas sociais originárias para que sirvam como reflexáo inicial ao estudo pluralista das origens dos atuais sistemas culturais do panorama latino-americano.

\section{As disparidades do Estado-Nafáo}

$\mathrm{Na}$ diversidade latino-americana prima um tipo de Estado-Naçáo que tenta imitar o modelo ocidental. A realidade resultante năo foi de total êxito. Muitas variedades, porém, podem ser assinaladas. Para começar, devemos citar a existência de territórios que não alcançaram plena independência política, caso de algumas ilhas do Caribe, como Porto Rico e certas zonas das Guianas, particularmente a francesa. Podese falar, no entanto, de Estados-Naçáo bem-constituídos, mesmo que neles se possa observar ter sido a plenitude da soberania restringida por formas de dependência. Além de a unidade do território nacional apresentar problemas de fronteiras náo resolvidos, seja com Estados vizinhos ou no interior de um território. Tome-se como exemplo de casos mais representativos Brasil, México, Argentina e Chile. Com distintas evoluçóes históricas, esses países chegaram a fundamentar um poder central, uma soberania territorial e um sistema administrativo burocrático relativamente eficiente.

Cada um desses exemplos é singular e a trajetória pela qual se chega a essa organização institucional é historicamente muito diversificada. A continuidade colonial do sistema português evitou a balcanizaçáo - ou seja, a fragmentação do território -, tendo o Estado sido fortalecido por uma política de expansão territorial, com a transferência dos centros hegemônicos do nordeste monocultor e escravocrata até a área carioca, pela implantação da burocracia portuguesa, emigrada da Europa por ocasiáo da invasão de Portugal pelas tropas de Napoleão. Pouco a pouco, com a economia do café e o nascimento do pólo industrial paulista, e depois com a mudança da capital para Brasília, na tentativa de dar coerência a velhos e novos territórios, o Brasil conseguiu vencer as tentativas de secessão e cultivou o mito da grande extensão territorial e da possibilidade de encontrar sempre áreas internas para a expansáo de seu sistema. Superou crises importantes, como reduzir a hegemonia britânica, solucionar o problema da aboliçáo da escravatura, mudar o império para um sistema republicano e superar as dissidências internas. Outro fator que ajuda a singularidade do modelo brasileiro são as necessidades de pronta soluçáo dos problemas mais imediatos. Pode- 
se dizer que neste campo houve pontos débeis devido à aguda diferenciação social e à implantação de uma populaçăo imigrante sem resolver a marginalizaçáo da populaçáo negra, tampouco a de origem indígena. Também pode-se dizer nunca ter sido aplicado o modelo de democracia política completa e que adotou modalidades de vida política favorecedoras de um sistema de corrupçáo generalizada.

Recordemos o caso mexicano. $\mathrm{O}$ antigo vice-reinado da Nova Espanha deixa uma herança colonial dominada pelo minério e por baciendas. Durante algum tempo sofre a reduçáo de seus territórios devido à expansão da fronteira norte-americana. A organização do novo Estado começa com o Porfiriato (regime do ditador Porfírio Dias), que implica um primeiro sistema de organizaçáo de um novo Estado. Isto afirmar-se-á após um período de revoluçōes sociais e agitaçóes diversas, cujo resultado final será o nascimento do sistema atual, com diminuiçáo do poder das forças armadas, regime de partido único, poder crescente da burocracia estatal, sindicalismo mais ou menos dirigido e crescentes desníveis sociais. De todos os modos, o sistema demonstra a capacidade para sobreviver com reformas parciais e controle de movimentos opositores. É difícil explicar a racionalidade dessa sobrevivência, mas ela existe $\mathrm{e}, \mathrm{em}$ alguns casos, mostra mais habilidade que os próprios bolcheviques. Não sem razáo pode-se argumentar que essa capacidade de sobrevivência permite retificaçóes de linha semelhantes às utilizadas pelo Vaticano. Mas é evidente que os problemas de fronteira com os Estados Unidos pesaram muito na evolução mexicana.

No extremo sul do continente está a República Argentina, afirmada em torno do predomínio de Buenos Aires e modernizada através de importante imigraçáo européia, que promoveu crescente participação das camadas médias daquele país. O populismo peronista coincide com a crescente pressão para a melhoria econômica dos setores populares. Como em outros países latino-americanos, mostra desníveis de vida e manifestaçóes culturais entre a Argentina do litoral atlântico, com o domínio de Buenos Aires, face às zonas mais tradicionais. Também produzirá fluxos migratórios internos e fronteiriços, motivados pela busca de melhoria do nível de vida.

Analisemos, finalmente, o Chile como último exemplo de Estado nacional. $O$ desenvolvimento do aparato estatal militar, formado durante sua expansáo territorial ao norte e ao sul, tem relaçáo com o desenvolvimento de formas de capitalismo agrário è mineiro, no qual há forte participaçáo de capital estrangeiro. O Estado procura formas de integração e recorre, em muitos casos, a reivindicações da populaçáo. Há intensas lutas sociais que culminam com a presidência de Salvador Allende e, 
a derrota, com a sua substituição por um sistema liderado pelas forças armadas, com forte participação norte-americana.

Entre casos extremos teríamos que enumerar uma larga série de situaçóes intermediárias, nas quais os regimes militares e de estruturação de tentativas estatais levaram a situaçóes como a atual crise peruana ou à bipolaridade no poder entre burocracia estatal, empresários do café e narcotraficantes, na Colômbia. Uruguai e Costa Rica são citados como modelos de democracia. A decadência da classe média uruguaia e a extensão da corrupção na Costa Rica trazem, contudo, sérias dúvidas a essa afirmação. A evolução do Panamá está evidentemente ligada à situação do canal e à instalação de um sistema bancário internacional. Dessa forma, como conclusão deste aparte, dever-se-ia chegar à descrição minuciosa das dificuldades da integraçáo política dos países da América Latina, que são muito diferentes e incoerentes em sua política exterior.

Podemos citar muitos casos específicos e cada um deles nos levaria a um capítulo especial. No entanto, o essencial é termos claro que a idéia de Estado-Nação, inspirada nos exemplos de países como Inglaterra e França, está passando por uma crise existencial. Além disso, no caso latino-americano, e em outros, não se deve esquecer que esses países cresceram e se desenvolveram sob condiçóes gerais de dependência, as quais muitas vezes afetaram sua capacidade de decisóes soberanas.

Assim, podemos adiantar que a diversidade de situaçóes presentes e passadas torna difícil a coordenação de esforços para a integraçáo política da América Latina. Dificuldade não significa impossibilidade. É muito provável que a integração seja facilitada, como em outras circunstâncias, pela crise nos grandes centros hegemônicos e pela necessidade de países da região adotarem medidas políticas que afetem a totalidade ou grande parte desse múltiplo conjunto.

\section{As diferenças entre os modelos de desenvolvimento}

Os economistas e, muito particularmente, a CEPAL (Comissáo Econômica para a América Latina) nos habituaram a estudos comparativos em busca de soluçóes (ampliação de mercados, desenvolvimento de indústrias e elevação de capacidade de consumo dos povos da América Latina), levados pela ignorância das particularidades históricas de distintas reaçóes e das diferenças de mentalidades e culturas de grupos sociais, cujo comportamento é muito diverso dos previstos nos grandes planos tecnocráticos. Esquematizaram-se excessivamente modelos sucessivos, que deveriam levar a uma meta final quase utópica.

Essa ignorância leva a um utopismo técnico inscrito dentro da 
ingênua posição dos supostos planos das Naçōes Unidas, que anunciavam várias décadas de desenvolvimento. A CEPAL acreditava na construção de modelos economicistas, nos quais a industrialização, a proteçáo aos preços dos produtos locais, a unificação de mercados regionais e o desenvolvimento da capacidade empresarial apareciam como palavras mágicas, capazes de modificar situaçóes de poder e promover grandes mudanças.

A experiência mostra as limitaçóes de tantos sonhos acumulados em montanhas de papel, que náo eram mais do que declaraçóes de intençóes. Certo é que esses textos serviam para justificar o crescimento de uma burocracia internacional custosa e cada vez mais numerosa. Deve-se reflexionar sobre o modo que nascem e evoluem os modelos desenvolvimentistas, mas como primeiro erro pode-se citar a falta de uma investigaçáo histórica adequada a cada região. Em segundo lugar, não se tem em conta a necessária alteração de fatores de poder para permitir essas transformaçóes. Em terceiro, é ilusão acreditar ser a formulação de um bom plano suficiente para que ele seja aplicado. Nisso pode-se rastrear as origens dessa crença até o fim do período colonial sob o reformismo bourbônico.

\section{$A$ diversidade de linguas}

Outro obstáculo para a integraçăo vem da diversidade dos idiomas. Além dos idiomas autóctones - como, por exemplo, o quéchua e o aymará -, existe um núcleo predominantemente de língua espanhola e outro de língua portuguesa. Há zonas específicas de antigo domínio inglês, francês e holandês, mas a diversidade de línguas não é obstáculo para a unidade européia. Ademais as novas formas de comunicação de massa, favorecidas pelos satélites e traduçóes simultâneas, além do impacto de diversos sistemas audiovisuais, superam as antigas barreiras geopolíticas.

Essa situação tem antecedentes remotos. A diversidade de idiomas não bloqueou a adoção de costumes, formas de alimentação, hábitos de consumo, sistemas de habitação, maneiras de vestir, manifestaçóes de recreaçáo, relaçóes entre pessoas ou raças. O meio-ambiente, as peculiaridades de cada território, a instalaçáo humana e o conjunto dos sistemas populacionais, as técnicas de produçáo e os múltiplos comportamentos coletivos demonstraram a permeabilidade da barreira idiomática. $O$ idioma nacional deixa-se influenciar e incorpora vocábulos e modalidades expressivas dos idiomas de outros povos. É assim que o francês se difundiu como segunda língua das elites nos fins do século XIX. Hoje nota-se um predomínio do inglês. 
A difusão do creole merece explicaçáo especial. Contrariamente à crença vulgar, não se trata da volta às línguas africanas, mas sim de verdadeira linguagem, fruto de fenômenos de contra-culturação, nos quais setores dominados buscam novas formas de expressão, mais fáceis e representativas.

Merece considerações especiais a difusão do guarani. $O$ índio paraguaio foi maltratado e marginalizado. Não obstante, a língua guarani é usada como meio de busca de uma identidade nacional, muitas vezes por filhos de imigrantes europeus, ou de outra procedência. Finalmente, para o intercâmbio cultural e para a integração, a diversidade idiomática é hoje um obstáculo menor do que foi no passado.

\section{$O$ ressurgimento de formas de marginalizafäo étnicas}

Outrora desejou-se dar valor científico à noçăo de raça. Hoje esse princípio está totalmente superado. Como explicar isso? A raça e os valores étnicos são superpostos a formas de estratificação social rígidas. Mas esses processos ocorrem em muitas partes do mundo, não somente na América Latina. As barreiras econômico-sociais estão relacionados às novas formas de subcultura da pobreza. Na América Latina é possível comprovar essas barreiras por formas de discriminaçáo encoberta no mercado de trabalho, dificuldades de instalação, alojamento, transporte etc. Tudo isso implica num pesado bandicap para a integração de certos grupos étnico-culturais. Explica também o surgimento de grupos neonazistas e tensóes étnicas, a difusáo de sectarismos religiosos e a severidade de certas políticas de controle de imigrantes.

Pelo mesmo motivo pode-se explicar a força irracional da defesa ou a agressão de certas atitudes que partem da constataçáo dessas barreiras sociais. Como exemplo, podemos mencionar algumas manifestaçóes que fazem da negritude, do indigenismo e do sexismo valor de combate para a constituição de lobbies intransigentes.

$O$ papel ambiguo das fronteiras sob os pontos de vista político, econdmico e sócio-cultural

As fronteiras políticas da América Latina, tanto no período colonial como em épocas mais recentes, nunca se apresentaram como barreiras ao intercâmbio. Digamos que o traçado da fronteira foi se transformando, à medida em que os territórios que pretendiam a independência pressionavam por mudanças ou eram sujeitos a transferências por imposiçóes de políticas realistas. Por outro lado, a própria fronteira revela-se totalmente permeável. Isto quer dizer que os Estados não conseguem impedir a livre circulaçáo de pessoas, costumes e idéias. Pode- 
mos enumerar múltiplos casos. Por exemplo, não foi possível impedir o comércio interfronteiriço e nem certos tipos de migraçōes humanas; muito menos quando fenômenos sociais mais sutis, como podem ser as manifestações religiosas, o intercâmbio de idéias ou de costumes. Assim, poderíamos inclusive afirmar que a fronteira atua como elemento de unidade e não de separação. Naturalmente, essa afirmação também é válida para as fronteiras políticas, como sugere a atual tendência à concentração demográfica em certas zonas fronteiriças.

Por esse motivo nos interessa pensar primordialmente em regiôes, mais do que em Estados, para classificar grupos sociais que se interinfluenciam e vivem em constante mutação. Muito mais complicado, porém, é determinar as especificidades regionais quando tentamos estudar o grau de influência dos novos meios de comunicação de massa.

\section{A verdadeira integração realiza-se em nível das culturas}

Depois dessas consideraçóes, podemos descobrir o essencial da afirmação: muito mais que projetos de difícil aplicaçáo ou acordos pouco animadores entre países, a grande conclusáo tirada do estudo da integração é que esta vai sendo realizada de maneira progressiva e irreversível a partir dos fenômenos culturais. Às vezes programados por decisóes de certos governos, na maioria dos casos, surgem de manifestaçóes espontâneas - atitudes, hábitos, opiniōes, por exemplo -, que não podem ser resultado de planejamento antecipado e colocado em prática por aparato legal.

Se fizermos uma análise do que poderíamos considerar como elemento essencial do processo de identidade latino-americana, comprovaremos que o mesmo se dá sob forma muito mais espontânea do que planificada e pode ser direcionado. Uma observaçáo objetiva da reaparição desta identidade faz surgir manifestaçóes não-previstas, resultado de uma nova situação mundial e de peculiaridades próprias à regiáo, que a diferenciam de outras regióes e podem no futuro facilitar um outro comportamento social, na busca de transformaçōes.

Por ser demasiadamente evidente não retrocedemos na análise histórica às semelhanças e afinidades nas raízes ibéricas das potências que foram os principais atores da conquista, ou seja, Espanha e Portugal; mas náo se poderá deixar de lado as tradições históricas do mundo ibérico, que às vezes as transformam em potências rivais, mas com muito mais elementos comuns do que os que tendem a diferenciá-las. 


\section{As formas de integração cultural na literatura,}

nas artes, na arquitetura, na música e nas ideias

Em todos esses campos podemos observar a permanência de variáveis que diferenciam a produçáo latino-americana da de outras regiōes do mundo. Desde os tempos de Gustavo Le Bon tratou-se de estudar esse fenômeno; mais adiante, os sociólogos tentaram aglutinar o pensamento latino-americano no chamado caráter nacional. Tendo essas tendências um teor quase racista, agora se enfatiza fundamentalmente a tentativa comum de encontrar-se uma identidade cultural que leve em conta não só o passado histórico, como também as influências geográficas, a composição das populações, os sistemas de produção, o babitat e as distintas maneiras de enfrentar as relaçóes com outras partes do mundo.

Esse procedimento torna-se visível no chamado boom literário que, com exagerada simplificação, tratou de explicar o surgimento e êxito de um tipo de literatura inscrito dentro de uma tendência geral sentida por todos os latino-americanos: inserção de realidades nacionais; expressão de desejos comuns; em alguns casos, busca de compromisso e recepção favorável por leitores que estavam à espera desse material. A expressão boom é limitada, por ser demasiadamente seletiva ao referir-se ao êxito editorial de alguns escritores e por ignorar um feito fundamental, que é o fato de a literatura latino-americana ter alcançado significação universal. Certa vez apontamos esse sintoma como indicador de amadurecimento cultural semelhante ao que possa ter ocorrido no mundo da literatura russa pré-revolucionária.

A concepção do boom restringiu-se falsamente a certos best sellers muito notórios ou à combatividade e à simpatia que despertava a atitude militante de alguns autores. Acreditamos que o juízo deve ser mais profundo e menos parcial. O que a literatura latino-americana começou a mostrar foi um grau de amadurecimento e criatividade náo conhecido até esse momento. As anteriores elites latino-americanas imitaram demasiadamente os modelos externos e foram menos criativas. Agora, pelo contrário, poderíamos dizer que essas limitaçóes foram, de alguma forma, superadas.

Nas artes plásticas podemos fazer observações semelhantes. A primeira atitude foi a de imitar os modelos europeus, como na literatura se havia imitado estilos literários. Um claro exemplo temos no catálogo de pintura equatoriana enviada à exposição universal de Paris no fim do século XIX. Ignorando os valores da pintura quitenha, optaram por remeter cópias de pinturas de escolas européias, detalhando a excelência 
da técnica empregada. A arquitetura recorre a normas técnicas sem desconhecer as condiçóes do meio e as dificuldades de adaptar-se a um tipo de sociedade em plena mudança, sempre dependente de uma natureza subcontinental. Evidentemente, à medida em que nos referimos a manifestaçóes de cultura superior, a perda do espírito imitativo não implica passar a uma etapa de credibilidade total. O mundo se intercomunica com maior facilidade: as viagens, os estudos no exterior, por exemplo, são mais freqüentes; os concursos internacionais são abertos a distintas nacionalidades. A chamada escola de Paris, o movimento da Baubaus, não distinguem nacionalidades, de modo que deve-se julgar a contribuição da influência externa conjuntamente com os acertos de interpretação regional em nível de pintura, como a de um Wilfredo Lam, um Cândido Portinari, um Pedro Figari, devendo-se perder a velha tendência a estudar tais manifestaçóes culturais como produto de excessiva influência local.

O folclore latino-americano é importante na medida que é produto espontâneo de condiçóes ambientais e históricas. Sobre isso pensamos fazer novas observaçōes posteriormente. A repercussão do folclore atravessa rapidamente fronteiras para encontrar um público cuja sensibilidade transcende regionalismos locais.

O tema da música nos permite indicar com maior facilidade as diferenças entre cultura popular e cultura mais refinada. A grande criatividade musical latino-americana começa tendo poderosa raiz na base de seu folclore. Pouco a pouco váo surgindo elementos que transcendem o nível da criação popular para integrar-se em manifestações de grande força criadora. Mas essa observação, que fazemos a propósito da música, não deve se reduzir à explicaçáo específica da criação musical. Em todos os campos de manifestação da cultura latino-americana, de uma maneira ou de outra, encontramos raízes históricas e locais que seráo levadas e difundidas por alguns representantes geniais, com repercussáo internacional.

Náo se poderia explicar um Carpentier sem estudar o Caribe e a influência formadora de Paris, nem o suposto europeísmo de Borges sem levar em conta a influência dos imigrantes e da cultura européia na sociedade de Buenos Aires. Em outros casos, as alternativas da vida política geraram formas de compromissos diversos. Finalmente, será muito difícil encontrar um autor desarraigado do meio que o produz, assim como uma região com manifestações culturais em um isolamento total.

Os fatores e as formas sociais que favorecem a integrafäo cultural 
Deve-se desconfiar das explicaçóes habituais que vềem a integração cultural como um processo social vertical, ou seja, imposto de cima para baixo. Náo são unicamente as maiores instituiçóes, nem os acordos governamentais, que favorecerão esta integraçáo com táo grandes limites para a consecuçăo de êxitos efetivos.

Estudos recentes mostram que devem ser consideradas formas mais espontâneas e, no entanto, de maior profundidade, nas quais a origem social popular apareça como favorável à adoção de medidas verdadeiramente integradoras. Nos setores pobres da população há maior facilidade na adoção de hábitos de consumo, formas de vida de povos vizinhos ou dos diversos imigrantes. Por isso, insistimos na ineficácia da noçáo de fronteira como autêntica barreira para a integraçáo cultural. $O$ elemento popular é fundamental nessa integração, quando a mesma se opera em profundidade. Neste sentido, nem a fronteira servirá para ilhar, nem a origem popular será um elemento de bloqueio.

Do mesmo modo que mencionamos o popular, devemos nos referir à poderosa contribuição da mentalidade dos jovens para este esforço integrador. Há uma inquietude da juventude de distintos setores da sociedade latino-americana, que estáo buscando raízes culturais para encontrar uma identidade e adotar medidas que resolvam seus problemas essenciais. Há certo tipo de atitude rebelde e não-conformista frente a sociedades demasiadamente rígidas - daí os preconceitos, as formas repressivas e os privilégios de certas minorias. Nessa rebelião juvenil há distintas maneiras de manifestar-se, já que a contestação pode ser política, social e, muitas vezes, cultural.

Ao lado dessa constatação sobre a importância do elemento popular e juvenil, vamos apresentar outros fatores que influíram e influem no processo de integração cultural.

Vejamos alguns exemplos.

- Os movimentos demográficos sob formas migratórias diversas

A população latino-americana, desde sua origem mais remota, caracteriza-se por distintas correntes migratórias e as múltiplas barreiras legais náo impediram essa tendência secular, condicionada pela instalação de povos em busca de terras novas, por formas de cultivo, circunstâncias climáticas, instauração de modelos sociais diferentes etc. Para compreender-se tal fenômeno basta levarmos em conta os diversos exemplos históricos. Nos últimos tempos acentuava-se o componente juvenil do êxodo rural e a instalaçáo urbana motivada por imigraçáo 
para países estrangeiros. A América Latina havia sido terra de imigrantes; agora há correntes latino-americanas que se dirigem ao hemisfério norte-industrial, tendo principalmente os Estados Unidos, o Canadá, os países da Europa Ocidental e a Austrália como casos mais representativos. O grande atrativo desses movimentos migratórios, assim, vem sendo o que se chama o Norte. Como exemplos notáveis podem ser mencionados os milhares de imigrantes ilegais colombianos que chegam, à margem de toda legalidade, para instalarem-se na Inglaterra ou na França, desde que se complicou seu ingresso aos Estados Unidos; ou imigraçóes inter-latino-americanas, como a dos chamados indocumentados da Colômbia, da Venezuela, ou a imigraçáo clandestina para o Brasil, Argentina etc.

\section{- As diversas trocas entre mentalidades, crenfas, opiniōes e comportamentos}

Nos estudos dessas mudanças a metodologia empregada tende a mudar progressivamente. Houve um tempo em que se pensou serem essas trocas detectadas verificando-se a influência da difusão de livros e, em particular, de autores, deixando-se levar pelo rigor metodológico da chamada História das idéias. É verdade que o catolicismo, o enciclopedismo, o liberalismo, o positivismo, o marxismo e o anarquismo constituem corpos coerentes que podem ser rastreados pela pesquisa em bibliotecas, traduçóes, publicações periódicas e análises de textos. No entanto, hoje vigora uma atitude mais cética com relação à importância exclusiva dos meios cultos de difusáo dessas idéias - porque influenciam diretamente as populaçōes analfabetas ou semi-analfabetas. Assim, nos tempos mais recentes verifica-se a crescente importância do rádio, do cinema e da televisão.

Do mesmo modo que as influências musicais transcendem às partituras, as mudanças de mentalidade não podem ser explicadas apenas através da difusão do pensamento escrito. A antropologia moderna nos dá bons exemplos da importância dos instrumentos e técnicas como o arco e a flexa, a domesticação de animais, as formas de cultivo, os sistemas alimentares que mostram essas diversas formas de interpenetração de povos.

Aspectos históricos e presentes dos problemas de saúde evidenciam a propagaçáo de carências alimentares, epidemias e outros elementos que nos permitem reconstruir a totalidade da história da condição biológica do homem latino-americano.

Essa atitude renovadora nos possibilita criticar a falta de autenticidade de certas campanhas orquestradas para estabelecer fronteiras cul- 
turais. Não é preciso muita astúcia para perceber que o culto à defesa do território e das fronteiras está, antes de tudo, ligado aos interesses dos Estados-maiores dos exércitos os quais, sobretudo, procuram a justificativa de sua existência e a consolidaçáo de sistemas de poder. Acabamos de passar por várias décadas de exagerada difusão das chamadas doutrinas de segurança nacional, hoje em decadência, pois serviram fundamentalmente para justificar os regimes repressivos, que atacavam as tendências à democratização, com o pretexto de impedir a expansão de um comunismo, o qual, hoje se compreende bem, não teria a menor possibilidade de história duradoura.

A situação mudou. Procura-se fortalecer as experiências democráticas, e, através da civilizaçáo do lazer, o homem interessa-se pelo contato mais próximo com a natureza, pela preservaçáo do meio-ambiente, pela busca de sistemas alimentares que não deteriorem a saúde, por combater o consumo de drogas - tabaco e álcool incluídos -, por viagens e conhecimento mais profundo da realidade nacional e das peculiaridades que náo sáo as suas. Do mesmo modo, o homem procura a transformação da história na revisáo dos antecedentes dos grandes problemas atuais, pesquisando soluçōes de uma problemática sem mitos, culto de heróis, nacionalismos chauvinistas e, nisso tudo, pode-se notar um amadurecimento cultural que tende a se impôr no território latinoamericano.

Esses elementos culturais importam por si mesmos e pela repercussão que seu conhecimento adequado deve exercer sobre a produção, o consumo e os intercâmbios entre as distintas partes da América Latina. Uma visão pessimista pode nos levar a dizer que: na atual conjuntura, há mais retrocessos que avanços; a carência de noçôes adequadas contribuiu poderosamente para o fracasso de muitas políticas que, movidas pelo desenvolvimentismo ingênuo e mercados comuns mal planificados, só foram aproveitadas por alguns grupos privilegiados.

Tudo o que até aqui foi dito não dá uma visão completa, mas serve para avançar algumas idéias de uma temática a ser coordenada e devidamente investigada. Conhecer a fundo os problemas da área latino-americana e a origem dos mesmos, bem como as relaçóes entre os povos que a integram, é base essencial para preparar o caminho das soluçóes adequadas. Do mesmo modo, não podemos deixar de destacar a necessidade de superar a etapa do latino-americanismo romântico e literário, para assinalar que se deve criar uma consciência madura e com capacidade operativa.

No mesmo sentido, deve-se considerar as especificidades de países 
e regióes compondo a área latino-americana - embora na busca de traços comuns que permitam maior proximidade e cooperação -, e o conjunto de fatores externos que influem sobre ela e sobre outras regiôes do mundo. A identificação dos traços comuns contribuirá para a adoção de medidas que facilitem as soluçōes. A situação atual não é a ideal. A inquietude intelectual, no entanto, pressiona por mudança de atitude e adoçáo de medidas que permitam aumentar a capacidade de políticas comuns. Admitir as diversidades não significa a negação da importância de caracterizaçóes comuns à cultura latino-americana.

\section{Avançamos até uma verdadeira integração ou a uma crescente disparidade entre regiões e sub-regióes?}

Neste trabalho não se buscou ser demasiadamente original, senão apresentar as distintas situaçóes, suas raízes históricas e os elementos positivos que póem em relevo o significado das culturas latino-americanas em seus elementos comuns e nas diferenças em cada regiáo. Há dois aspectos que deveriam ter desenvolvimento anterior: tentar determinar a origem e as modalidades da dinâmica das mudanças culturais e a aguda globalização da cultura mundial como causa da modernização das comunicaçóes e da pressão da mídia.

Considerando que a integraçáo cultural se apresenta como um processo muito variado, fundamentalmente espontâneo, pouco afetado até agora pela adoçáo de medidas de governos, devemos levar em conta que a civilização industrial e a expansão dos modelos difundidos por economia e tecnologia ocidentais não implicam criar um mundo sempre igual, sem variações locais e com participação mínima das sociedades dependentes.

Se o grande dilema que devemos resolver é a busca de uma nova ordem internacional, necessária para a paz e a harmônica integração de todos os povos, ele náo será solucionado através da imposiçăo de uma forma cultural qualquer. Estamos em uma etapa de agitaçóes e conflitos, de reivindicaçóes das diversidades, de busca de fórmulas renovadoras, de saudável relaçăo entre as especificidades interiores das raízes de cada povo.

Reforça-se a difusão mundial de sistemas de ensino e de comunicação mais ou menos uniformes. Mas isso deve ser feito respeitando-se as modalidades de cada sociedade. Por outro lado, torna-se evidente que a verdadeira democracia nasce da democratizaçáo do poder local, com a máxima participação dos membros de cada comunidade. Neste período 
o mundo está submetido a intensas mudanças; é difícil ser otimista a curto prazo, mas mesmo em suas fases mais negativas, que váo da imposiçăo de modelos únicos a integrismos religiosos diversos, toda construção, para ser eficaz, deve prestar a devida atenção a muitos dos problemas aqui enumerados sobre as culturas latino-americanas.

Insistindo sobre os sistemas educativos, mostra-se evidente estarem submetidos a enorme pressão, que faz dos diplomas um meio fundamental para incorporar os jovens ao mercado de trabalho, tão conturbado pela adoção de tecnologias que afetam a mão-de-obra tradicional. Da mesma forma, deve-se dar prioridade à instrumentaçáo de controles e defesas contra a imposição de normas de consumo e modelos de vida difundidos pelos novos meios de comunicação de massa.

Nesta situação de mudanças e de sombrias perspectivas, as reservas culturais da América Latina proporcionarão os elementos para resistir à simples imitaçáo e ao automatismo passivo.

\title{
Resumo
}

A integração da América Latina enfrenta dificuldades e obstáculos devido à diversidade de culturas, às características específicas do Poder Estatal de cada país $\mathrm{e}$ às diferenças de scus modelos de desenvolvimento. A integração avança a partir de fenômenos culturais que fundamentalmente são espontâneos. O êxito desse processo exige o respeito às diversidades de cada regiâo e a busca de fórmulas renovadoras.

\begin{abstract}
The Latin America's integration copes with difficulties and hindrances due to de diversity of cultures, to the specific characteristics of each country's State Power and to the differences of development models. The integration is holds embedded in cultural phenomena that are fundamentally spontaneous. The success of this process requires attention to the diversity of each region and the search for renewed formulas.
\end{abstract}

Gustavo Beybaut, historiador, é professor titular do Instituto de Altos Estudos da América Latina da Universidade de Paris III. De 17 de setembro a 17 de novembro de 1993, ocupou a Cátedra Símon Bolívar, implantada no IEA, em abril de 1992, através de convênio firmado entre a USP e a Fundaçāo Memorial da América Latina.

Palestra feita pelo autor no IEA-USP em 11 de agosto de 1993. 